\title{
A potential therapy of human umbilical cord mesenchymal stem cells for bone regeneration on osteoporotic mandibular bone
}

\author{
Nike Hendrijantini ${ }^{1}$, Tuti Kusumaningsih ${ }^{2}$, Rostiny Rostiny ${ }^{1}$, Pungky Mulawardhana ${ }^{3,4}$, \\ Coen Pramono Danudiningrat ${ }^{5}$, Fedik Abdul Rantam ${ }^{6}$
}

Correspondence: Dr. Nike Hendrijantini

Email: nike-h@fkg.unair.ac.id

\begin{abstract}
'Department of Prosthodontic, Faculty of Dental Medicine, Universitas Airlangga, Surabaya, Indonesia, ${ }^{2}$ Department of Oral Biology, Faculty of Dental Medicine, Universitas Airlangga, Surabaya, Indonesia, ${ }^{3}$ Department of Obstetrics and Gynecology, Medical Faculty, Universitas Airlangga, Surabaya, Indonesia, ${ }^{4}$ Department of Obstetrics and Gynecology, Dr. Soetomo Hospital, Surabaya, Indonesia, ${ }^{5}$ Department of Oral and Maxillofacial Surgery, Faculty of Dental Medicine, Universitas Airlangga, Surabaya, Indonesia,

${ }^{6}$ Department of Microbiology and Virology, Faculty of Veterinary Medicine, Universitas Airlangga, Surabaya, Indonesia
\end{abstract}

\section{ABSTRACT}

Objective: The aim of this study is to prove that human umbilical cord mesenchymal stem cell (hUCMSC) therapy on mandibular osteoporotic model is able to increase transforming growth factor-beta-1 (TGF)- $\beta 1$ expression, Runx2, and osteoblasts. Materials and Methods: This research is true experimental posttest control group design. Thirty female Wistar rats were divided into 6 groups randomly, which consisted of sham surgery for control (T1), ovariectomy as osteoporotic group (T2), osteoporotic group injected with gelatine for 4 weeks (T3), 8 weeks (T4) injected with hUCMSC-gelatine for 4 weeks (T5) and 8 weeks (T6). All mice were presented for immunohistochemistry examination for TGF- $\beta 1$, Runx2, and histology for osteoblasts. Results: The lowest level of osteoblast was osteoporotic group injected with gelatine in 4 weeks compared to other groups. There were increases of TGF- $\beta 1$, Runx2, and osteoblasts from osteoporotic group compared to osteoporotic post-hUCMSC-gelatine injection group. Conclusion: The hUCMSC has a high osteogenic effect and increases the osteoporotic mandibular bone regeneration on the animal model that is showed by the increase of the level of TGF- $\beta 1$, Runx 2 , and osteoblasts.

Key words: Human umbilical cord mesenchymal stem cells, mandibular, osteoporosis

\section{INTRODUCTION}

Dental implant is implanted in the jaw bone as well as the original tooth and supposed to be more comfortable to the patient. Dental implant is mostly

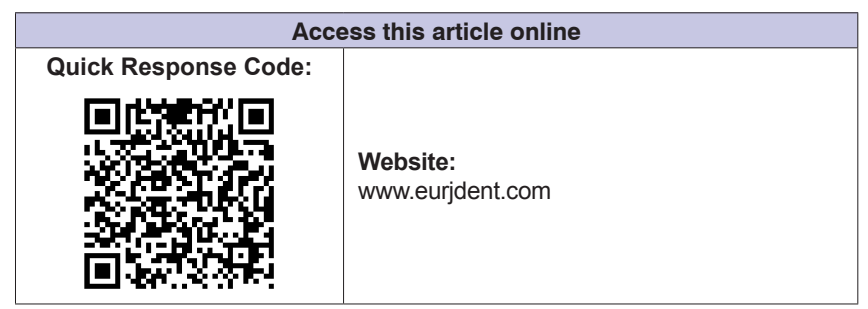

done in elderly patients. ${ }^{[1]}$ Elderly patients are often having osteoporosis caused by menopausal factors.

This is an open access journal, and articles are distributed under the terms of the Creative Commons Attribution-NonCommercial-ShareAlike 4.0 License, which allows others to remix, tweak, and build upon the work non-commercially, as long as appropriate credit is given and the new creations are licensed under the identical terms.

For reprints contact: reprints@medknow.com

How to cite this article: Hendrijantini N, Kusumaningsih T, Rostiny $R$, Mulawardhana P, Danudiningrat CP, Rantam FA. A potential therapy of human umbilical cord mesenchymal stem cells for bone regeneration on osteoporotic mandibular bone. Eur J Dent 2018;12:358-62.

DOI: 10.4103/ejd.ejd_342_17 
Menopause is a phase in which the menstrual cycle stops and the hormonal in women rapidly vanishes. ${ }^{[2]}$ Osteoporosis results a rejection of an implant due to the absence of good osseointegration between the implant and the bone. ${ }^{[3]}$ In recent studies, the regeneration of bone osteoporosis in long bones of animal model tries to show pledge results; $;^{[4]}$ however, the role of mesenchymal stem cells (MSCs) in the regeneration process in the mandible bone has not been studied yet.

Recently, MSCs from newborn umbilical cord known as human umbilical cord MSCs (hUCMSCs) which is multipotent, began to be widely considered as MSCs choices. hUCMSCs are tended to be stored in tissues storage as the alternative of stem cells therapy in a various type of diseases or disorders. ${ }^{[5]}$ However, hUCMSC experiments for the application of mandibular bone tissue engineering have not been performed.

Transforming growth factor-beta-1 (TGF)- $\beta 1$ is a growth factor with the biggest resource in bones that control bone formation by increasing proliferations and osteoblast differentiations. ${ }^{[6]}$ TGF- $\beta 1$ is a kind of protein that is secreted to control the regulation of cell proliferations, differentiations, and death which interacts with estrogens. ${ }^{[7]}$ Runx 2 is a transcription factor that starts and controls early osteogenesis and final mineralization of bones. ${ }^{[8]}$ This research is conducted to know the potency of hUCMSCs on the therapy of osteoporosis mandibular bone regeneration to increase the bone density.

\section{MATERIALS AND METHODS}

\section{Sample preparation}

Ethical commission of health research of RSUD Dr. Soetomo Surabaya and Faculty of Veterinary Medicine of Universitas Airlangga has approved this study. This study is a true experimental study. Three months 180-200 g of 30 female Rattus norvegicus Albinus strain Wistar were collected as sample. These samples were divided into 6 groups randomly, normal group with sham surgery (T1), ovariectomy group with 4 weeks (T3) and 8 weeks (T4) of injection of gelatin solvent, ovariectomy group with 4 weeks (T5) and 8 weeks (T6) of hUCMSCs and gelatin injection.

\section{Ovariectomy preparation}

Ovariectomy was prepared for osteoporotic condition using Khajuria method, ${ }^{[9]}$ and sham surgery was performed for control group. The mice were allowed for 12 weeks to conduct an osteoporosis.

\section{Human umbilical cord mesenchymal stem cell culture establishment preparation}

Umbilical cords were retrieved from healthy C-section babies at RSUD Dr. Soetomo Surabaya, Indonesia. The cords were cut into $1 \mathrm{~cm}$ length; the arteries, veins, and adventitia layers were separated to attain Wharton's jelly. Wharton's jelly then was processed based on Han's method, ${ }^{[10]}$ and then, the medium was changed every 3 days.

Human umbilical cord mesenchymal stem cell injection and gelatine solvent procedure on mandibular of osteoporotic mice

The anesthesia was applied to the samples. A perforation process was conducted on the left mandibular of the samples through the skin beneath molar area with perforator needle (Stabident, Miami, USA) to trabecular area; then, the needle was retrieved. Each rat in the T3 and T4 groups was injected with $50 \mu \mathrm{l}$ of gelatin solvent while $\mathrm{T} 5$ and $\mathrm{T} 6$ groups were injected with 400,000 cells in $50 \mu \mathrm{l}$ of gelatin solvent.

The termination of experimental animals and microscopic examination of research specimens

A termination process on mice was conducted after the duration of the research was achieved. The examination of the osteoblasts level, hematoxylin and eosin stained using Mayers (Sigma Aldrich, St Louis, USA) was used. Immunohistochemistry staining using monoclonal mouse TGF- $\beta 1$ antibody (Novus Biologicals, USA) and monoclonal mouse Runx2

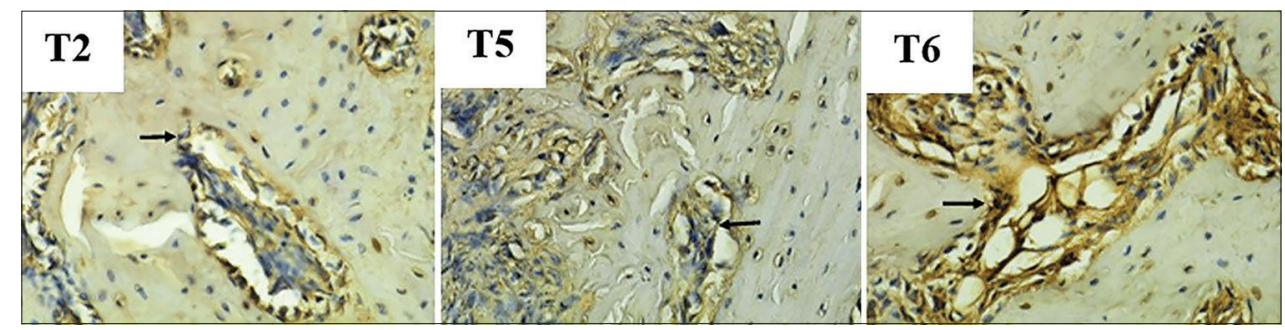

Figure 1: The microscopic result of expression transforming growth factor- $\beta 1$. Arrows show transforming growth factor-beta- 1 expression on immunoreactive osteogenic cell 
antibody (Novus Biologicals, USA) was conducted. The microscopic observation was performed using light microscope (Nikon H600L, Tokyo, Japan), equipped with DS-Fi2 300 megapixel digital camera and Nikon Image System picture editor software. Data were calculated using index scale of Remmele for immunohistochemistry and count the total of osteoblast cells (surface osteoblast and mesenchymal osteoblast) on five different fields of view in $\times 400$ magnification.

\section{Statistical analysis}

All the data were represented in six different experimental groups. Statistical analysis was performed using ANOVA through SPSS software version 15.0 (SPSS, Inc., Chicago, IL, USA). $P<0.05$ score was considered to be significant statistically.

\section{RESULTS}

Isolation and culture of human umbilical cord mesenchymal stem cells

Isolation and culture of hUCMSC have been published yet. The result of that study was confirmed that the cell was hUCMSC by determining the surface marker of the isolate cell, that is, $\mathrm{CD}^{-} 5^{-}, \mathrm{CD}^{+} 3^{+}, \mathrm{CD}^{+}$, and CD 105+.[11]

The expression of transforming growth factor-beta-1, Runx2, and level of osteoblasts

The expression of TGF- $\beta 1$ is microscopically shown in Figure 1. The amount of TGF- $\beta 1$ expression in each group was depicted in the mean and standard deviation values in Figure 2. There was an increase

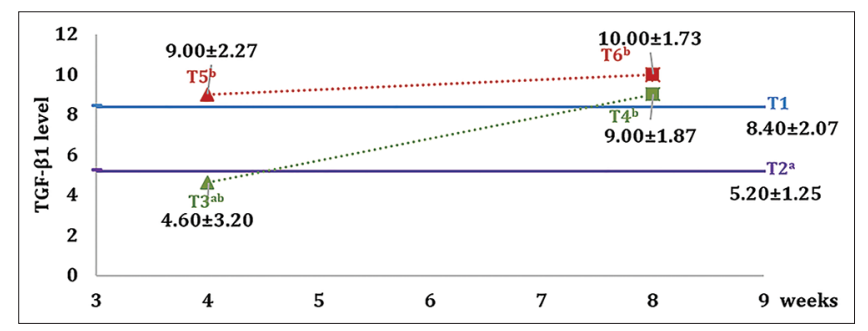

Figure 2: Graph of mean value and standard deviation of each group on transforming growth factor-beta-1 expression. Different superscripts show a statistically significant difference $(P<0.05)$ of TGF- $\beta 1$ expression in the group with hUCMSC compared to the other groups. The lowest amount of TGF- $\beta 1$ expression was discovered in the osteoporotic model group (T2).

The expression of Runx 2 is shown in Figure 3. The number of Runx2 expressions in each group is shown in the mean and standard deviations in Figure 4. The highest Runx2 expression is found in the group with hUCMSC compared with the other groups.

The osteoblast level is microscopically shown in Figure 5. Figure 6 shows mean value and standard deviation for each group. The highest number of osteoblasts is found in the group with hUCMSC compared with the other groups.

\section{DISCUSSION}

The differentiation of MSC to osteoblasts is a complex process that requires synergies from regulating factors in the microenvironment. Adequate synergies will lead to activation of MSC differentiation to certain lineages through some specific transcription regulators. The differentiation of MSCs to osteoblast needs some growth factors and transcription factors including TGF- $\beta 1$ and Runx $2 .{ }^{[6]}$

The last studies show that MSC on osteoporotic group would cause a decrease in production of TGF- $\beta 1$. The result showed a decreasing in production of estrogen as the consequence of ovariectomy on mice, which decreases the production of TGF- $\beta$. It causes an increase in osteoclast activity and a decrease in osteoclast apoptosis. ${ }^{[12]}$ Another study tended to perform different activity by providing TGF- $\beta$ in which this would cause an increase in differentiation of osteoblasts and increasing trabecular bone formation and also reducing bone loss in the osteopenia model caused by estrogen deficiency. ${ }^{[13]}$ Alterations of the production and cell response toward growth factor would affect abnormality in bone formation. ${ }^{[4]}$

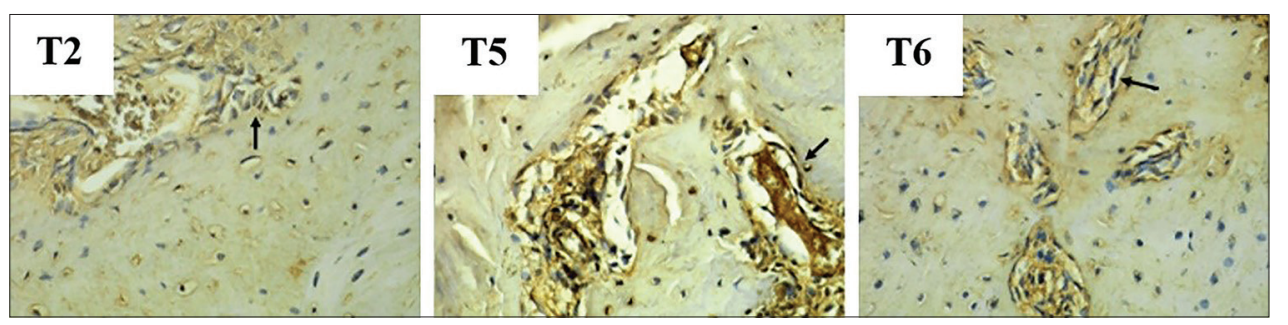

Figure 3: The microscopic result of expression Runx2. Arrows show Runx2 expression on immunoreactive osteogenic cell 
TGF- $\beta 1$ is the largest growth factor in human bone. TGF- $\beta 1$ was produced by osteoblasts as inactive propeptides and it incorporated into bone matrices. TGF- $\beta 1$ inhibits osteoclast activity and stimulates proliferation and differentiation of preosteoblasts to support bone formation. ${ }^{[14]}$ TGF- $\beta 1$ would be mobilized by the osteoclasts after running on the bone matrix and would attract the MSC to the site of bone resorption for osteoblast differentiation. ${ }^{[15]}$

The expressed of Runx2 by MSCs caused the differentiation into osteoblast lineage and inhibits its differentiation into another lineage. ${ }^{[16]}$ Experiments using calvarial cells with negative expression of Runx2 would cause differentiation changes to adiposity. ${ }^{[15]}$ Runx2 is an important transcription factor in osteogenic differentiation, one of which is the stimulation of transcriptional gene formation in osteoblasts, such as osteocalcin. ${ }^{[16]}$

In the osteoblastogenesis process, there was an increase in osteoblast in T5 and T6 group. The osteoblasts would be produced by MSCs that performed osteogenic differentiation. ${ }^{[13]}$ Li discovered that MSC expression in osteoporotic group decreased significantly. This is in line with the results of this study in which it obtained a lower osteoblast cells due to the occurrence of MSC defects in osteoporotic group. The osteoinductive response would decrease significantly in osteoporotic group. ${ }^{[17]}$ The decreasing of stem cell ability to proliferate and differentiate that occurred in menopause group would lead to

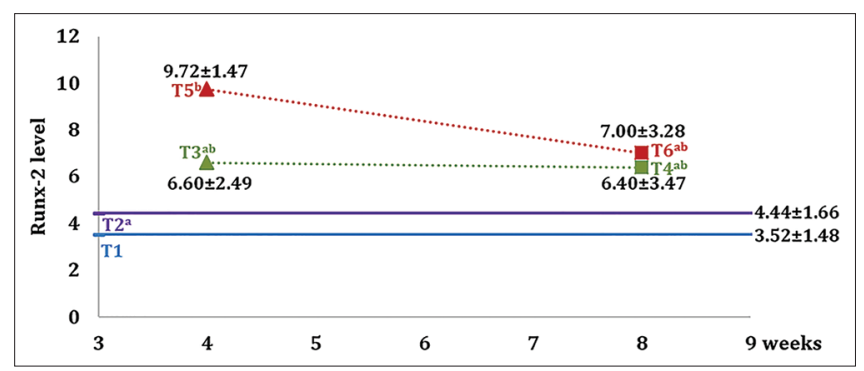

Figure 4: Graph of mean value and standard deviation of each group on Runx2 expression. Different superscripts show a statistically significant difference $(P<0.05)$ a decreasing in osteogenic cells and reduction of mineralized matrix that caused osteoporosis. ${ }^{[18]}$ Other studies showed that by administering MSC to the osteoporotic group where MSC defects occur, it would cause differentiation of MSC into a number of osteoblasts and induced bone formation. ${ }^{[17]}$

In this study, the result also showed a lower osteoblast cells in the 8-week hUCMSC group than 4 weeks. This seems to be the cause of process of bone formation, which started from 30 days after bone resorption to 90 days in the trabecular bone. ${ }^{[19]}$ Providing hUCMSCs in osteoporotic mice would result in increased osteoblastogenesis ability. Runx 2 would be produced by MSC and osteoprogenitor, to ensure MSC differentiates specifically into osteoblasts. ${ }^{[20]}$ Several growth factors would help to stimulate osteoblast differentiation, such as TGF- $\beta 1$, which is a potent osteotropic polypeptide. TGF- $\beta 1$ conducted the proliferation and osteoblast differentiation. ${ }^{[19,21]}$ The result showed that by providing hUCMSCs would increase the occurrence of osteogenic differentiation. It is indicated with the increase of Runx 2 and TGF- $\beta 1$ indicators.

\section{CONCLUSION}

An increase of TGF- $\beta 1$ expression, Runx2, and the number of osteoblasts on osteoporotic mice that were induced by hUCMSCs shows that there is an increase in osteoblastogenesis activity. The result states that

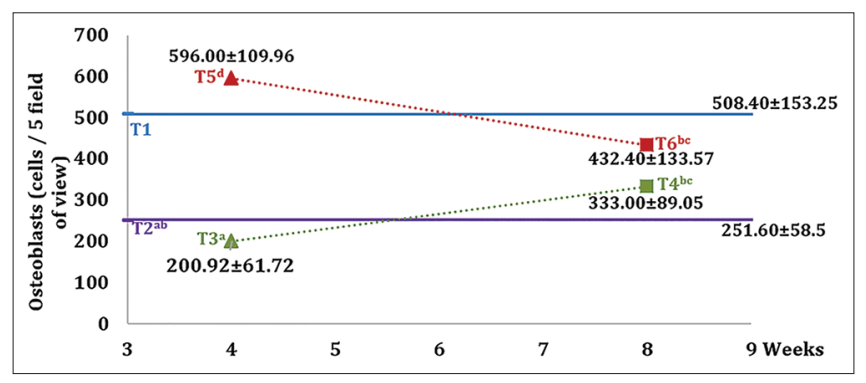

Figure 6: Graph of mean values and standard deviation of each group on the osteoblasts. Different superscripts show a statistically significant difference $(P<0.05)$

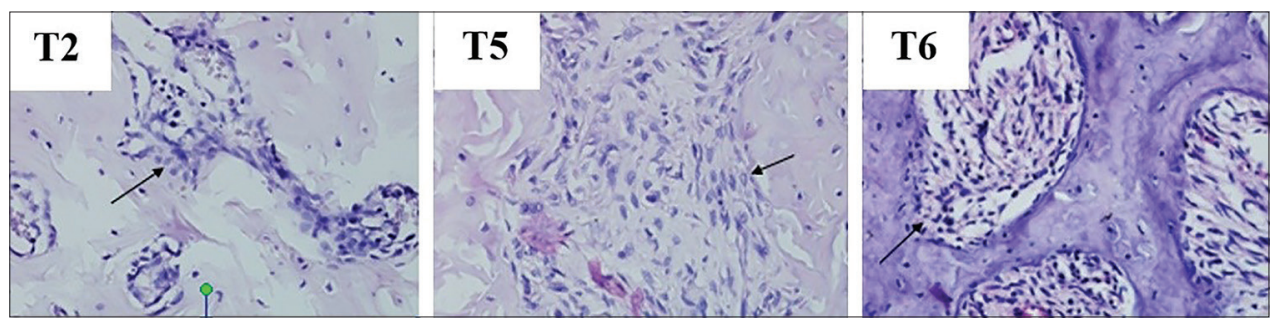

Figure 5: The microscopic result of osteoblast examination on mice jaw. Arrows show the osteoblast cells 
the treatment of jaw bone tissue engineering would be managed by an induction of hUCMSCs from the other side.

\section{Financial support and sponsorship Nil.}

\section{Conflicts of interest}

There are no conflicts of interest.

\section{REFERENCES}

1. Misch CE. Rationale for dental implants. In: Contemporary Implant Dentistry. $3^{\text {rd }}$ ed. St. Louis, Canada: Mosby Inc.; 2008. p. 3-21.

2. Guyton AC, Hall JE. Text Book of Medical Physiology. $12^{\text {th }}$ ed. Philadelphia: Saunders, Elsevier; 2011. p. 1070-6.

3. Becker W, Hujoel PP, Becker BE, Willingham H. Osteoporosis and implant failure: An exploratory case-control study. J Periodontol 2000;71:625-31.

4. Wang Z, Goh J, Das De S, Ge Z, Ouyang H, Chong JS, et al. Efficacy of bone marrow-derived stem cells in strengthening osteoporotic bone in a rabbit model. Tissue Eng 2006;12:1753-61.

5. Ding DC, Chang YH, Shyu WC, Lin SZ. Human umbilical cord mesenchymal stem cells: A new era for stem cell therapy. Cell Transplant 2015;24:339-47.

6. Kasagi S, Chen W. TGF-beta1 on osteoimmunology and the bone component cells. Cell Biosci 2013;3:4.

7. Abbas AK, Lichtman AW, Pillai S. Cellular and Molecular Immunology. Philadephia: Elsevier Saunders; 2017. p. 266-70.

8. Siddiqui S, Arshad M. Osteogenic potential of punica granatum through matrix mineralization, cell cycle progression and Runx-2 gene expression in primary rat osteoblasts. Daru 2014;22:72.

9. Khajuria D, Razdan R, Mahapatra D. Description of a New Method of Ovariectomy in Female Rats. 14 ${ }^{\text {th }}$ ed. Bangalore: Springer; 2012.

10. Han YF, Tao R, Sun TJ, Chai JK, Xu G, Liu J, et al. Optimization of human umbilical cord mesenchymal stem cell isolation and culture methods. Cytotechnology 2013;65:819-27.

11. Hendrijantini N, Kresnoadi U, Salim S, Agustono B, Retnowati E, Syahrial I, et al. Study biocompatibility and osteogenic differentiation potential of human umbilical cord mesenchymal stem cells (hUCMSCs) with gelatin solvent. J Biomed Sci Eng 2015;8:420-8.

12. Hughes DE, Dai A, Tiffee JC, Li HH, Mundy GR, Boyce BF, et al. Estrogen promotes apoptosis of murine osteoclasts mediated by TGF-beta. Nat Med 1996;2:1132-6.

13. Marie PJ, Kassem M. Osteoblasts in osteoporosis: Past, emerging, and future anabolic targets. Eur J Endocrinol 2011;165:1-0.

14. Langdahl BL, Carstens M, Stenkjaer L, Eriksen EF. Polymorphisms in the transforming growth factor beta 1 gene and osteoporosis. Bone 2003;32:297-310.

15. Pino AM, Rosen CJ, Rodríguez JP. In osteoporosis, differentiation of mesenchymal stem cells (MSCs) improves bone marrow adipogenesis. Biol Res 2012;45:279-87.

16. Prall WC, Haasters F, Heggebö J, Polzer H, Schwarz C, Gassner C, et al . Mesenchymal stem cells from osteoporotic patients feature impaired signal transduction but sustained osteoinduction in response to BMP-2 stimulation. Biochem Biophys Res Commun 2013;440:617-22.

17. Li C, Wei G, Gu Q, Wang Q, Tao S, Xu L, et al. Proliferation and differentiation of rat osteoporosis mesenchymal stem cells (MSCs) after telomerase reverse transcriptase (TERT) transfection. Med Sci Monit 2015;21:845-54.

18. Ma L, Aijima R, Hoshino Y, Yamaza H, Tomoda E, Tanaka Y, et al. Transplantation of mesenchymal stem cells ameliorates secondary osteoporosis through interleukin-17-impaired functions of recipient bone marrow mesenchymal stem cells in MRL/lpr mice. Stem Cell Res Ther 2015;6:104.

19. Kini U, Nandeesh BN. Physiology of bone formation, remodeling, and metabolism. In: Fogelman I, Gnanasegaran G, Van der Wall H, editors. Radionuclide and Hybrid Bone Imaging. Berlin: Springer; 2012. p. 29-57.

20. Chen G, Deng C, Li YP. TGF- $\beta$ and BMP signaling in osteoblast differentiation and bone formation. Int J Biol Sci 2012;8:272-88.

21. Garrett I. Anabolic agents and the bone morphogenic protein pathway in current topics in developmental biology. San Antonio: Elsevier Inc.; 2007. 